\title{
US provides immunity from legal claims related to three Ebola vaccines
}

\author{
Michael McCarthy
}

Seattle

The United States has granted immunity against legal claims related to the manufacture, testing, development, distribution, and administration of three vaccines for Ebola virus disease, said Sylvia M Burwell, US Health and Human Services secretary, on 9 December.

The immunity was issued under the provisions of the Public Readiness and Emergency Preparedness (PREP) Act, a 2005 law designed to facilitate the development of medical countermeasures to urgent public health needs, such as chemical, biological, radiological, and nuclear agents of terrorism, as well as epidemics and pandemics.

PREP Act declarations provide immunity only for claims brought before a US court and generally do not protect against claims made abroad or claims that result from actions or failures to act that constitute willful misconduct.

"My strong hope in issuing this PREP Act declaration in the United States is that other nations will also enact appropriate liability protection and compensation legislation," said Burwell. "As a global community, we must ensure that legitimate concerns about liability do not hold back the possibility of developing an Ebola vaccine, an essential strategy in our global response to the Ebola epidemic in west Africa."

Burwell's declaration provides legal protection under US law for three vaccine candidates:

- GlaxoSmithKline's Recombinant Replication Deficient Chimpanzee Adenovirus Type 3 Vectored Ebola Zaire Vaccine, known as ChAd3-EBO-Z;

- BPSC1001 vaccine (rVSV-ZEBOV-GP), made by BioProtection Services, a subsidiary of NewLink Genetics; and
- Ad26.ZEBOV/MVA-BN-Filo vaccine, manufactured by Janssen, a subsidiary of Johnson \& Johnson/Bavarian Nordic.

The declaration went into effect on 3 December. ${ }^{1}$

Since the law's enactment PREP Act declarations have been issued to cover vaccines used in $\mathrm{H} 5 \mathrm{~N} 1$ pandemic influenza clinical trials in 2008, products related to the H1N1 influenza pandemic, and countermeasures for anthrax, smallpox, acute radiation syndrome, and botulism.

In addition to providing liability protections the PREP Act authorized a fund to compensate people who had experienced serious injury as a result of the countermeasure administered or used under a PREP Act declaration. To qualify, the injury must have warranted hospitalization, whether or not the person was actually hospitalized, or have led to significant loss of function or disability. Compensation includes medical expenses, lost wages, and survivor death benefits.

The BMJ has chosen Médecins Sans Frontières as its 2014 Christmas charity. Find out how to donate at http://bit.ly/12pPyH3. Many thanks for your support.

1 US Department of Health and Human Services, Office of the Secretary. Ebola virus disease vaccines-notice of declaration under the Public Readiness and Emergency Preparedness Act. 10 Dec 2014. https://s3.amazonaws.com/public-inspection. federalregister.gov/2014-28856.pdf.

Cite this as: BMJ 2014;349:g7608

๑ BMJ Publishing Group Ltd 2014 